\title{
A Reserch Paper on Management of Library
}

\author{
Lalit Mohan Joshi \\ M.tech Scholar \\ BTKIT Dwarahat, Almora, Uttarakhand
}

\begin{abstract}
Library is place where all kind of books are available. An Intranet Library Management system defind as a web based application. This system contains list of all the books and can be accessed by remote users concurrently from any where in the campus. But for that users must be registered user.

Client sends requests, on receiving the request the server processes it and extracts the data from database and sends the result back to the client. This system provides separate interface and login for librarian, students and faculties. Librarian can modify database.

Users can search for books and renewal books online. They can recommend for new books by just sending messages to the librarian from any where in the college. They can view the issue and return dates of any book and due they have to pay. This system generates reports that can be used in analyzing the library performance.Thus the management can take appropriate steps to improve the facilities.
\end{abstract}

\section{Keywords}

Library, Books, Database, Programming Languages, Library Management Syatem, Server, Client, Data Flow Diagram, Modules

\section{INTRODUCTION}

Library Management System consists of record lists about the management of the details of the students and the issues going on as well as about some books and all. It is refer as webbased application. The project has three main modules namely- User, Registration, Librarian. According to the Modules the Distributor and Sub Distributors can manage and do their activities in easy manner as well as in sequence

As the modern organizations are automated and computers work as per the instructions, it becomes essential for the coordination of human beings, commodity and computers in a modern organization. This information helps the distributors to purchase or sale the products very efficiently.

The administrators and all the others can communicate with the system through this project, thus facilitating effective implementation and monitoring of various activities of the distributor of a supermarket.

\subsection{System Analysis}

\subsubsection{Existing System}

Problems accur in physical system are described below :-

- If one is not very careful then there is a possibility of issuing more than one book to a user.

- There is a possibility of issuing a book to a user, whose membership is not there.
- When a book is requested by the user, one has to physically check for the presence of a book in the library.

- Answering management query is like a time consuming process.

- Daily keeping a manual record of changes taking place in the library such as :- If the Library size is bigger then book being issued, book being returned e.t.c. can become cumbersome

\subsubsection{Proposed System}

The LIBRARY MANAGEMENT SYSTEM is defind as a software application which avoids more manual hours in taking the book, that need to spend in record keeping and generating reports. Maintaining of user details is complex in manual system in terms of agreements, royalty and activities. This all have to be maintained in ledgers or record of books. Co-coordinators also need to verify each record for small information.

- Easy search of book in the online library.

- Manual work is avoided.

- User no need to go to the library for Issue any kind of book, Stay online he or she can renew a book.

\subsubsection{Objective of the System}

The goal of the system is to speed up the activities, to bring down the work load with the increased efficiency. With this it is very easy to process course fee that is collected time to time from registered students those studying at franchisees.

\section{SYSTEM SPECIFICATIONS \\ 2.1 Hardware Requirements}

- $\quad$ Pentium-IV (Processor).

- 256 MB Ram

- $\quad 512$ KB Cache Memory

- Hard disk $10 \mathrm{~GB}$

- Microsoft Compatible 101 or more Key Board

\subsection{Software Requirements}

- Operating System : Windows 95/98/XP with MS-office

- Programming language: .NET2.0, VISUAL STUDIO2005

- Web-Technology : ASP.NET

- Back-End : SQL SERVER 2005

- Web Server : IIS 


\subsection{Design}

Design is the first step in the development phase for any techniques and principles for the purpose of defining a device, a process or system in sufficient detail to permit its physical realization.

Once the software requirements have been analyzed and specified the software design involves three technical activities - Design, Coding, Implementation and Testing that are required to build as well as verify the software.

The design activities are of main importance in this phase, because in this activity, decisions ultimately affecting the success of the software implementation and its ease of maintenance are made. These decisions have the final bearing upon reliability as well as maintainability of the system. Design is the single way to translate the customer's requirements accurately into finished software as well as in a system.

Design is the place where quality is fostered in development. Software design is a process through which representation of software translated by requirements. Software design is conducted in two steps. Preliminary design is concerned with the transformation of requirements into data.

\subsection{Data Flow Diagrams}

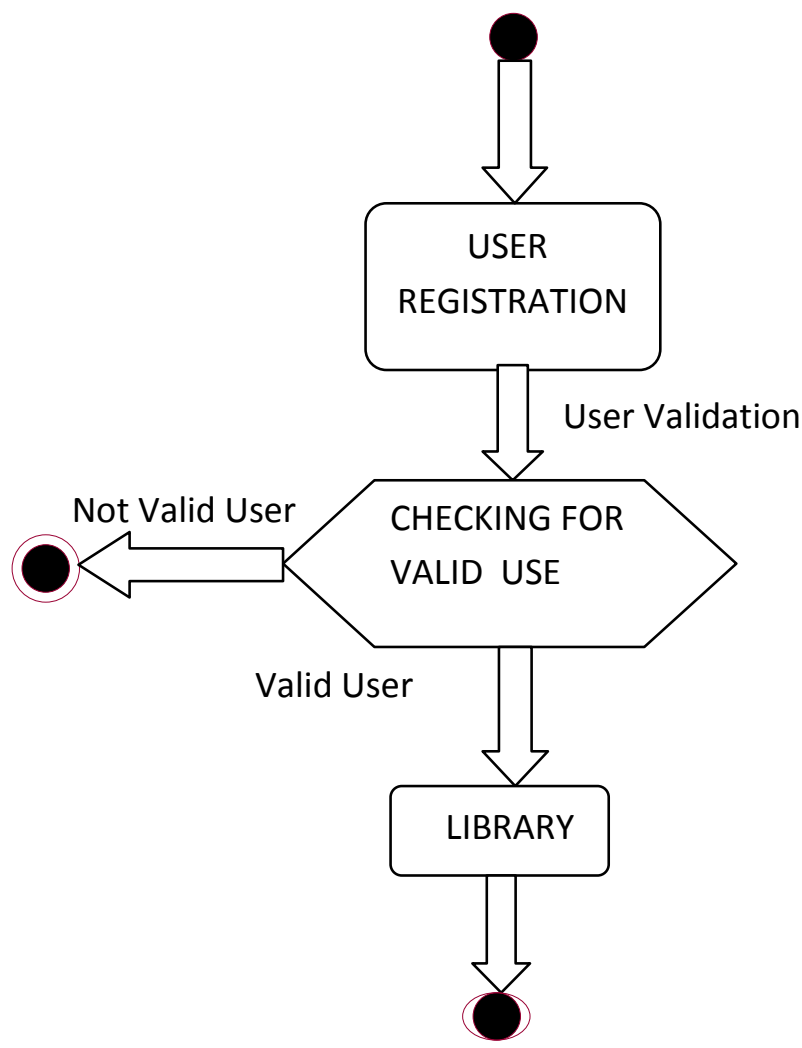

Fig. 0.1

The DFD takes an input-process and output view of a system i.e. Data objects flow into the software then transformed by processing elements at last the resultant data objects flow out of the software.

Data objects represented by labeled arrows and transformation are represented by circles also called as bubbles. DFD is presented in a hierarchical fashion i.e. the first data flow model represents the system as a whole. Subsequent DFD refine the context diagram (level 0 DFD), providing increasing details with each subsequent level.

A context-level DFD for the system the primary external entities produce information for use by the system and consume information generated by the system. The labeled arrow represents data objects or object hierarchy.

\subsection{Modules Used}

The proposed system categories and follows these modules to implement

\section{Login component}

1. Administrator(Head office manager)

2. Librarian

3. User

\section{Administrator Component}

\section{Administrator}

\section{Librarian Manager Component}

\section{Librarian Manager Student Component}

\author{
1. Books Details \\ 2. Issue Details \\ 3.
}

\subsection{Modules Descripstion}

User: User can use Library online by using login id and password where user can search for books as well as renewal books online. They can recommend for new books in the college by just sending messages to the librarian from any where. They can view the issue and return dates of any book and due they have to pay.

Registration: In the Registration module, user has to register himself or herself by supplying his personal information which gets store in data base which are using as backend. By registering himself or herself user will get his/her login id and Password so that he can access Library online. Individual Register form should be designed for individual user like(Student, Faculty, Librarian) and separate login has to provided for each user. For example if the users are students then student id should be SH001,for faculty id should be FC001

Librarian: Librarian is a person who manages the Library. Librarian has the permission that he can access the database. Librarian perform following tasks like:
a- Addition of a book
b- Modification of a book
c- Deletion of a book
d- Searching of a book
e- Managing of a book 


\subsection{Technologies Used}

\subsubsection{Front End Technology}

\section{Microsoft .NET Framework}

The .NET Framework is a new computing platform that simplifies application development in the highly distributed environment of the Internet. The .NET Framework is designed to fulfill the following objectives:

i. To provide a consistent object-oriented programming environment whether object code is stored and executed locally as well as remotely, but Internet-distributed.

ii. To provide a code-execution environment that minimizes software deployment and versioning conflicts.

iii. To provide a code-execution environment that guarantees safe execution of code, including code created by a semi-trusted third party or by an unknown.

iv. To provide a code-execution environment by eliminating the performance problems of scripted or interpreted environments.

v. To make the developer experience consistent across widely varying types of applications, such as Windows-based as well as Web-based applications.

To build all communication on industry standards to ensure that code based on the that any other code integrated by .NET Framework

\subsubsection{Back End Technology}

\section{About Microsoft SQL Server 2000}

Microsoft SQL Server is a Structured Query Language (SQL) based, client/server relational database. Each of these terms describes a fundamental part of the architecture of SQL Server.

\section{DATABASE}

A database is similar to a data file in that it is a storage place for data. A database does not present information directly to a user like a data file,; the user runs an application that accesses data from the database and presents it to the user in an understandable format.

A database typically has two components: first one is file holding the Physical Data Base and Second one is the Database Management System (DBMS) software that applications use to access data. For enforcing the database structure DBMS is responsible, including:

In between data in the database. Maintain the relationships.

- Ensure that data is stored correctly and rules those defining data relationships are not violated.

In case of system failures recovered all data to a point of known consistency

\subsection{Database Models}

ADO.NET API via an intermediate database through applets resulted server resulted in a new type of database model which is different from the client-server model. It is named as single tire, two tire and multi tire architecture based on number of intermediate server through the request should go.

\subsubsection{Single Tier}

In a single tier the server and client are the same in the sense that a client program that needs information (client) and the source of this type of architecture is also possible in java, in case To store the data flat files are used. However this is useful only in case of small applications. The simplicity and portability of the application developed is the main advantages of this

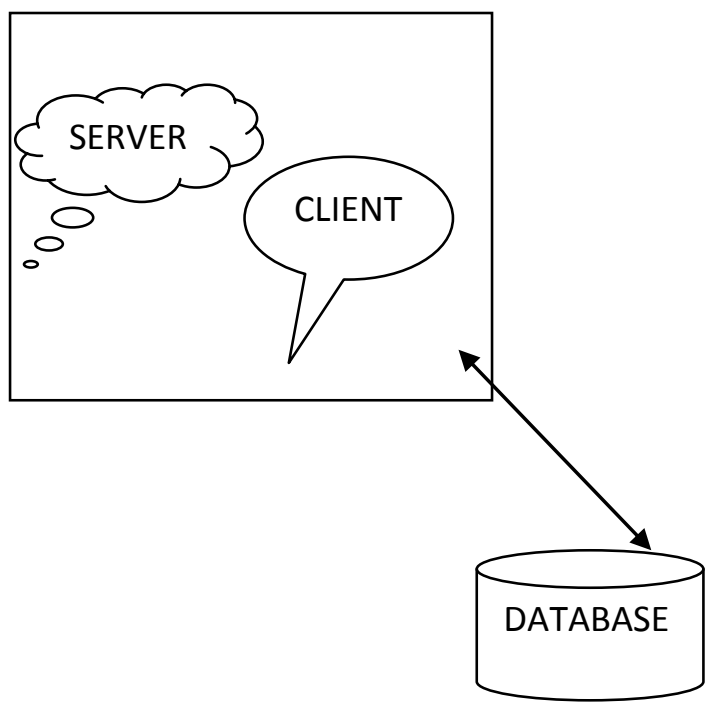

Fig. 0.2

\subsubsection{Two Tier (Client-Server)}

In two tier architecture the database resides in one machine and client in different machine they are connected through the network. A database management takes control of the database and provides access to clients in a network In this type of architecture. The Server is called as Software Bundle. On the other way Requesting for information Software in different machines, are called as the clients.

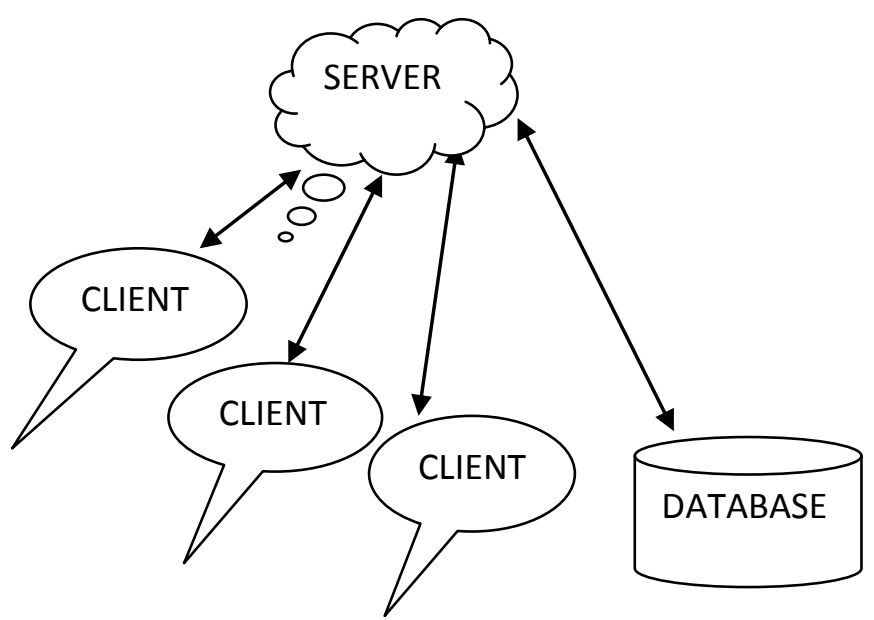

Fig.03 


\subsection{Database tables}

Table 1. Insert Book

\begin{tabular}{|l|l|}
\hline BOOKID & INT, \\
\hline TITLE & VARCHAR(150), \\
\hline AUTHOR & VARCHAR(100), \\
\hline YEARPUBLISHED & VARCHAR(20), \\
\hline CATEGORY & VARCHAR(100), \\
\hline PUBLISHER & VARCHAR(100), \\
\hline EDITION & VARCHAR(50), \\
\hline COST & VARCHAR(20), \\
\hline DATEOFENTRY & DATETIME, \\
\hline LIBRARYCOPY & INT, \\
\hline STATUS & VARCHAR(20), \\
\hline CONDITION & VARCHAR(20) \\
\hline
\end{tabular}

Table 2. Library Books

\begin{tabular}{|l|l|}
\hline BOOKID & INT NULL, \\
\hline TITLE & VARCHAR(150) NULL, \\
\hline AUTHOR & VARCHAR(100) NULL, \\
\hline YEARPUBLISHED & VARCHAR(20) NULL, \\
\hline CATEGORY & VARCHAR(100) NULL, \\
\hline PUBLISHER & VARCHAR(100) NULL, \\
\hline EDITION & VARCHAR(50) NULL, \\
\hline COST & VARCHAR(20) NULL, \\
\hline DATEOFENTRY & DATETIME NULL, \\
\hline LIBRARYCOPY & INT NULL, \\
\hline STATUS & VARCHAR(20) NULL, \\
\hline CONDITION & VARCHAR(20) NULL \\
\hline
\end{tabular}

Table 3. Issue book

\begin{tabular}{|l|l|}
\hline TRNSID & INT NULL, \\
\hline ROLLNUMBER & INT NULL, \\
\hline
\end{tabular}

\begin{tabular}{|l|l|}
\hline NAME & VARCHAR(150) NULL, \\
\hline AGE & INT NULL, \\
\hline GENDER & VARCHAR(10) NULL, \\
\hline BRANCH & VARCHAR(10) NULL, \\
\hline YEAR & INT NULL, \\
\hline BARTYPE & VARCHAR(15) NULL, \\
\hline BOOKID & INT NULL, \\
\hline TITLE & VARCHAR(150) NULL, \\
\hline AUTHOR & VARCHAR(150) NULL, \\
\hline CATEGORY & VARCHAR(100) NULL, \\
\hline EDITION & VARCHAR(20) NULL, \\
\hline PUBLISHER & VARCHAR(50) NULL, \\
\hline LIBRARYCOPY & INT NULL, \\
\hline ISSUEDATE & DATETIME NULL, \\
\hline DUEBACKBY & DATETIME NULL \\
\hline
\end{tabular}

\section{TESTING}

The testing phase is an important part of software development. This phase will help in automate process of finding errors with missing operations and also a with a complete verification to determine whether the objectives are met and tas well as user requirements are satisfied.

Software testing is carried out in three steps:

\subsection{Unit Testing}

It is a type of testing where in each module is tested to determine any missing operations, to verify whether the objectives have been met and also to provide its correctness, validity. Errors are corrected immediately and noted down. Unit testing is the important and major part of the project. So errors are rectified easily in particular module with program clarity is increased. In this project entire system is divided into several modules and is developed individually. For individual modules unit testing is conducted.

\subsection{Integration Testing}

It need not be the case, the software will also show perfect results when run as a whole whose modules run individually and showing perfect results,. The individual modules are clipped under this major module and tested again and verified the results. This is due to poor interfacing, which may results in data being lost across an interface. A module can have adverse, inadvertent effect on any other or on the global data structures, causing serious problems.

\subsection{Validation and Testing}

It is the phase of testing which determines the software functions as the user expected. Here also some modifications were. it is satisfied fully by the end user in the completion of the project. 


\title{
5. IMPLEMANTETION
}

\author{
1. HOME PAGE:-
}

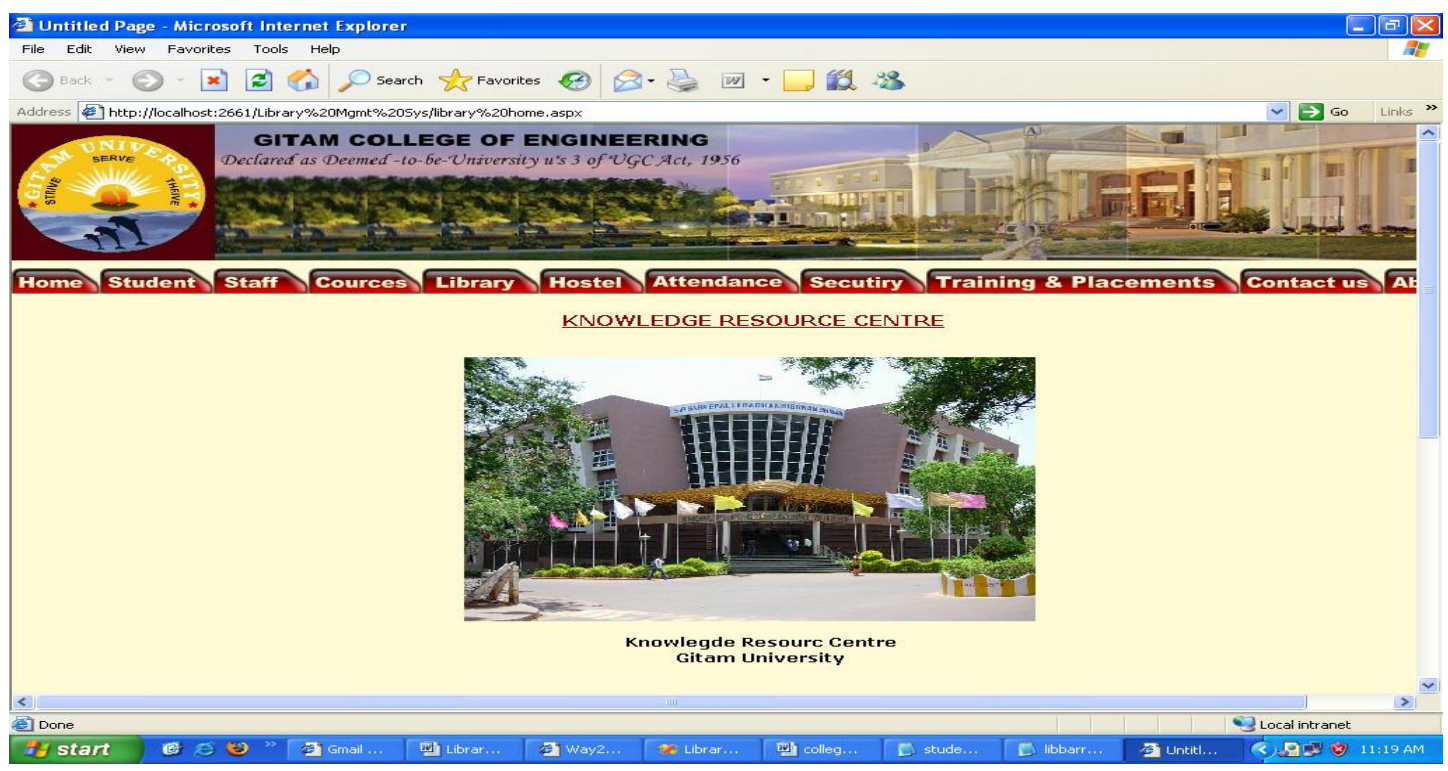

2. Library Home:-

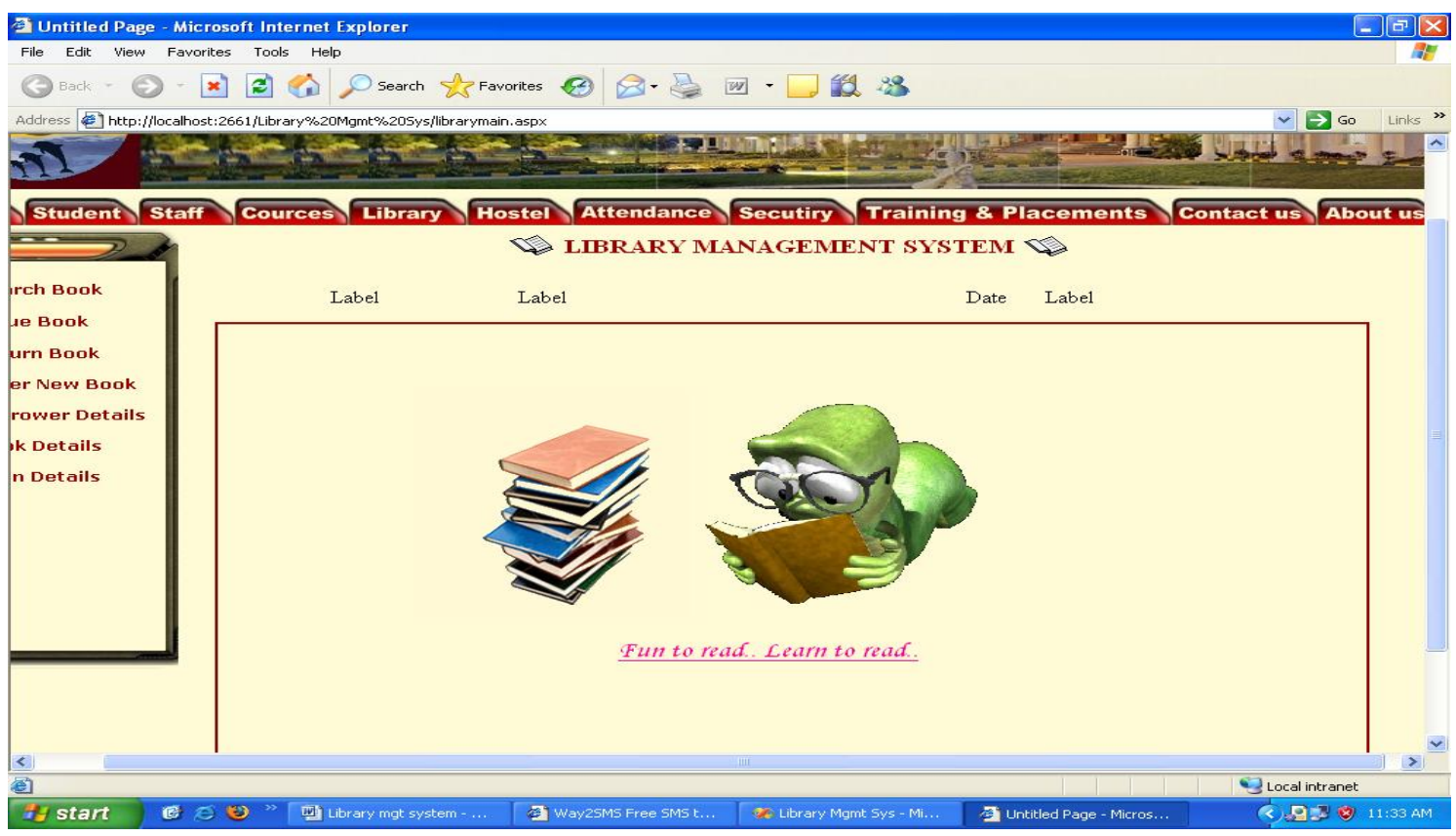


3.Book Search:-

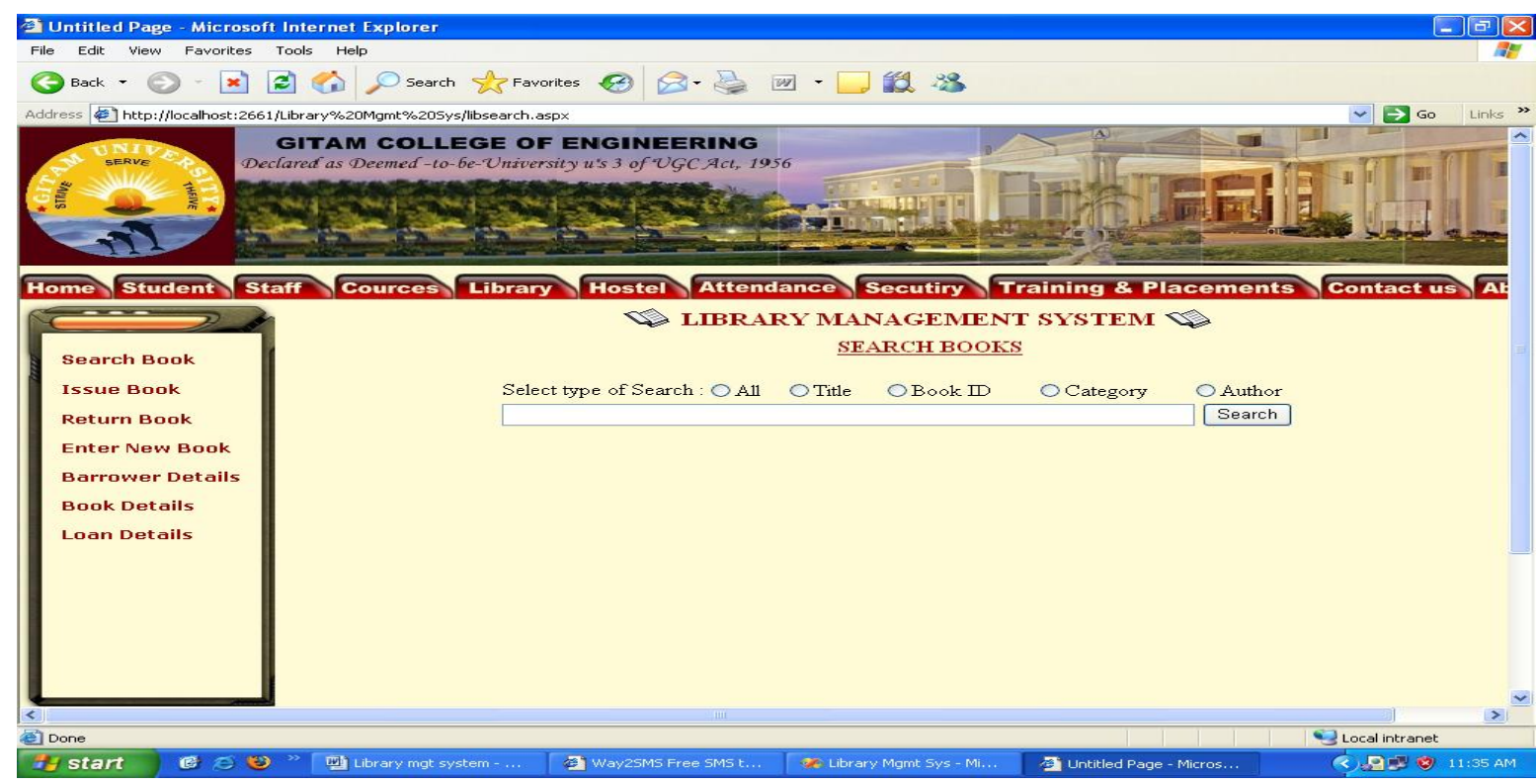

4.Issue of book

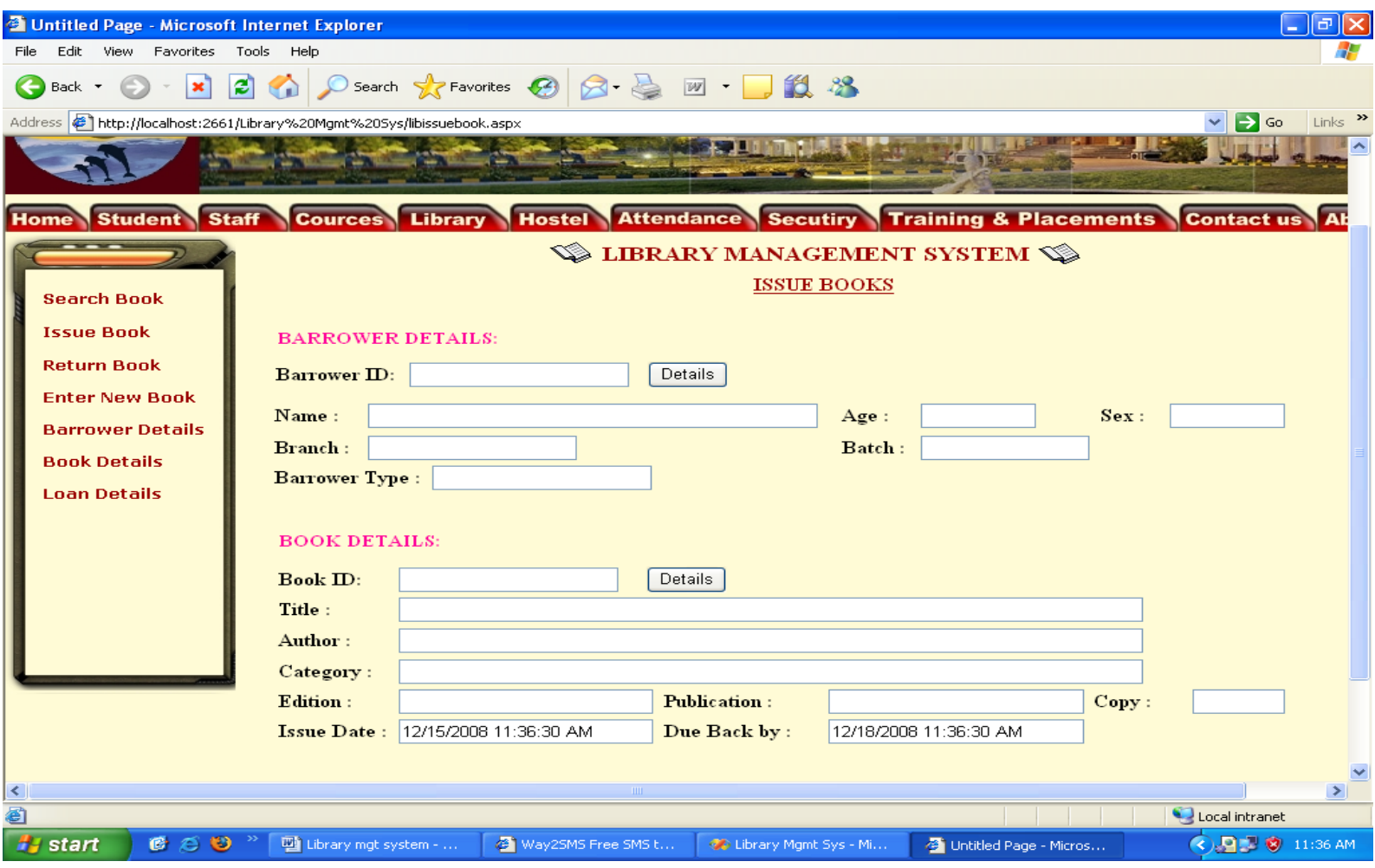


5. Return Book

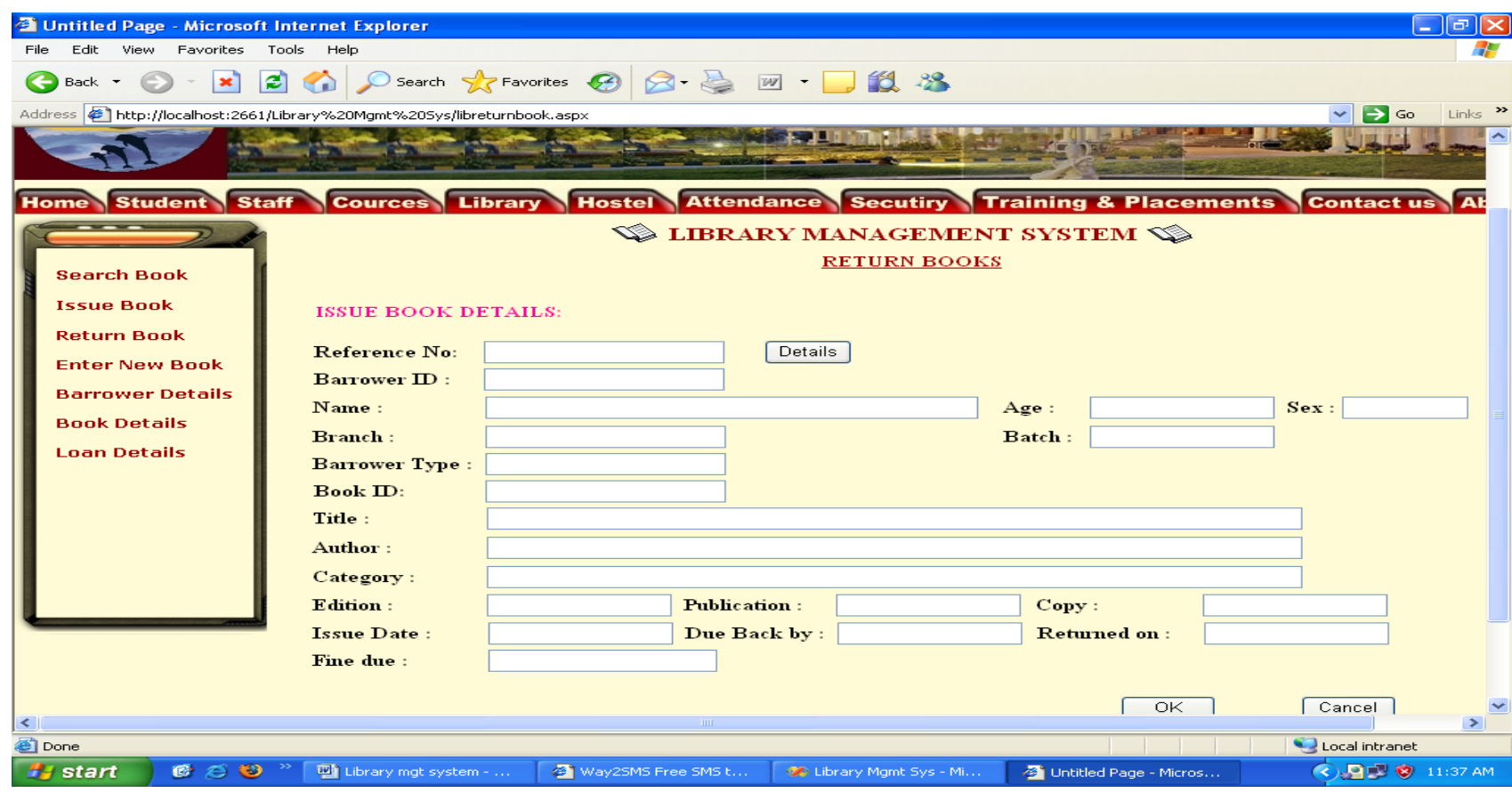

6.New Book Details.

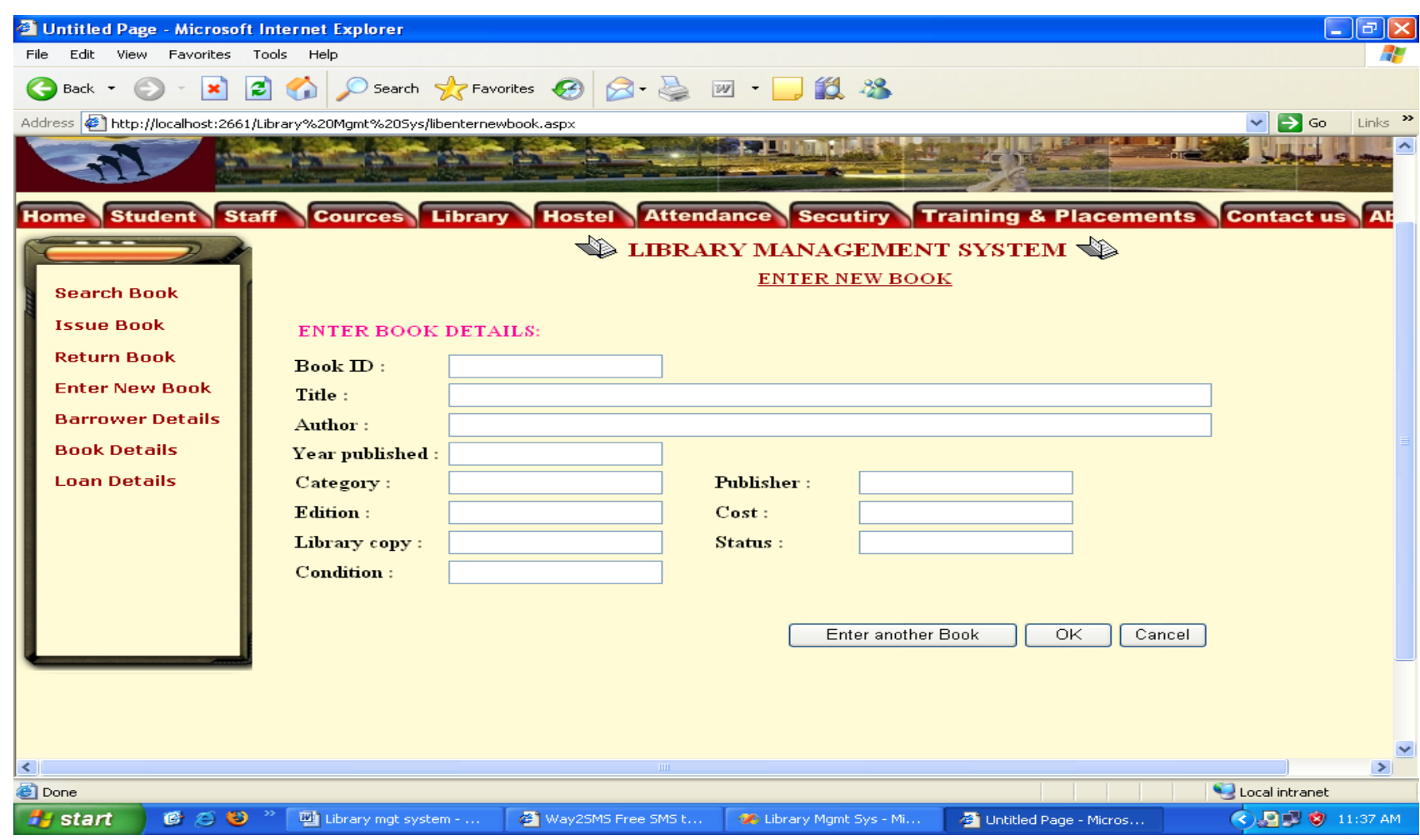




\section{CONCLUSION}

The future modifications can be done easily the package was designed in such a way. The following conclusions can be deduced from the development of the project.

- Library Management System of the entire system improves the efficiency.

- It provides a friendly graphical user interface which proves to be better when it is compared to the existing system.

- It gives appropriate access to the authorized users depending on their permissions.

- It effectively overcomes the delay in communications

- Updating of information becomes so easier

- Data security, Reliability and System security are the striking features.

- For modification the System has adequate scope in future, if it is necessary.

\section{REFERENCES}

[1] Blunden-Ellis John and Graham Margaret E., 'A UK market survey of library automation vendors (19921993)', Program 28(2), 1994,109-124.

[2] Blunden-Ellis John, 'A UK market survey of library automation vendors (1990-1991)', Program 26(3), 1992, 291-305.

[3] Bryant Philip, 'Making the most of our libraries', British Library Research and Innovation Report 53 1997, 1-113

[4] Brack Verity, 'Service developments at the RIDING Z39.50 gateway', New Review of Information and Library Research 5, 1999, 135-144.

[5] Burnett Peter, 'Emerging from the bibliographic wilderness: catalogue automation in the Bodleian Library, University of Oxford', Cataloging and Classification Quarterly 30(1), 2000, 51-72

[6] Chambers Shirley and Perrow David, Introducing project management techniques at the Robinson Library, University of Newcastle, Journal of Librarianship and Information Science 30(4), 1998, 249-258.

[7] Chappell Stephen and Thackeray Annie, 'TINlib: why and how the Arts Council chose this integrated software system to run its library', Program 26(4), 1992, 387-392
[8] Dempsey Lorcan, Russell Rosemary and Kirriemui John, 'Towards distributed library systems: Z39.50 in a European context', Program 30(1), 1996, 1-22.

[9] Edwards Adam J., 'Heritage IV: new system installation at Central School of Speech and Drama', Vine 115, 1999 , 24-33

[10] Fitzgerald S. and Flanagan J., 'UNICORN at Kew: computerising the libraries and archives at the Royal Botanic Gardens Kew', Program 27(4), 1993, 331-340.

[11] Haines Margaret, 'The year of the UNICORN: a review of the first year's experience with the UNICORN collection management system at the King's Fund Centre', Program 26 (2), 1992, 165-176

[12] Heseltine Richard, 'New perspectives on library management systems: a Pilgrim's Progress', Program 28 (1), 1994, 53-61

[13] Leeves Juliet, 'Automation of ILL management system', Interlending and Document Supply, 21 (3), 1993, 18-25

[14] McDonald Andrew and Stafford Janet (eds.), Self-service in academic libraries: future or fallacy? Proceedings of of a conference organised by Information Services, University of Sunderland, in conjunction with SCONUL held at St. Peter's Campus, University of Sunderland, 24/26 June 1996. Sunderland: University of Sunderland Press, 1997

[15] Moran, B.; Stueart, R.; Morner, C. (2013). Library and Information Center Management. California: Libraries Unlimited. ISBN 978-1-59884-989-9.

[16] Muirhead Graeme A., 'Current requirements and future prospects for systems librarians', Electronic Library, 12 (2) $1994,97-107$

[17] Myhill Martin R, ' Time for change: a personal insight into library systems' implementation: experiences at Exeter University Library', Program 34(1), 2000, 89-101

[18] Pachent Guenever, 'Network 95: choosing a third generation automated information system for Suffolk Libraries and Heritage', Program 30(3), 1996, 213-228

[19] Rowley Jennifer, 'GENESIS: a new beginning or a new generation', Electronic Library 12(5) 1994, 277-283

[20] Stafford Janet, 'Self issue - the management implications. The introduction of self-servcie at the University of Sunderland', Program 30(4), 1996,375-383 